www.jmscr.igmpublication.org

Impact Factor (SJIF): 6.379

Index Copernicus Value: 79.54

ISSN (e)-2347-176x ISSN (p) 2455-0450

crossrefDOI: https://dx.doi.org/10.18535/jmscr/v6i12.51

Journal Of Medical Science And Clinical Research

IGM Publication

An Official Publication of IGM Publication

\title{
A Clinical Study of Secondary Post Partum Haemorrhage at R.I.M.S Imphal, Manipur
}

\author{
Authors \\ Dr Haelom Liegise ${ }^{1 *}$, Dr Chirom Pritam Kumar Singh ${ }^{2}$ \\ ${ }^{1}$ Former Junior Resident, Dept of Obstetrics and Gynaecology, R.I.M.S Imphal, Manipur \\ ${ }^{2}$ Associate Professor Dept of Obstetrics and Gynaecology, R.I.M.S Imphal, Manipur
}

\begin{abstract}
Objectives: To determine the various factor associated with secondary PPH and to evaluate the medical or surgical intervention needed in secondary PPH.

Methods: The study was a hospital based, carried out in a tertiary hospital of Manipur, Regional Institute of Medical Sciences, Imphal. It was a prospective longitudinal study. It was conducted during the period of November 2014 to April 2016. Sixty five women with bleeding per vagina with a diagnosis of secondary postpartum haemorrhage and subsequently getting admitted during the study period were included in the study.
\end{abstract}

Results: In the study conducted, the majority of women were in the age group of 20-30 year (63.1\%).The mean age was 27. \pm 6.04 . Parity in the present study did not influence the incidence of secondary PPH, and the distribution of its causes was the same in both primiparous and multiparous women. In 17(26.2\%) secondary PPH presented less than 7 days of delivery, 24(36.9\%) within 8-14 days, 14(21.5\%) within 1521 days,4(6.2\%) within 22-28 days and 6(9.2\%) beyond 29 days with $P=15.91 \pm 9.30$. The cause of secondary postpartum haemorrhage was retained bits of membrane 24(36.9\%\%), retained placental tissue $14(21.5 \% \%)$, purpural sepsis 8(12.3\%) and subinvolution of the uterus 19(29.2\%).Out of 65 women with secondary PPH 32(49.2\%) women received medical treatment in the form of uterotonic drugs and administration of antibiotic. Surgical treatment was given to 33(49.2\%)women, check evacuation was done on $26(40 \%)$ women, Dilatation and evacuation $(D \& C)$ in $4(6.2 \%)$, placental tissue were removed digitally in 2(3.1\%) where the cervical os was open and haemostaic suture was taken in 1(1.5\%) women with bleeding from the right cervical angle.

Conclusion: Secondary PPH is a rare complication but one that can result in severe maternal morbidity. We found that retained placental tissue and bits of membrane were the commonest cause of secondary PPH followed by subinvolution of the uterus and puerperal sepsis. Medical and surgical intervention were required in almost all the cases with equal frequency.

\section{Introduction}

Secondary postpartum haemorrhage is defined as any abnormal or excessive bleeding from the birth canal occurring between 24 hours $^{1}$ and 6 weeks postpartum $^{2}$ and, as this definition includes no reference to the volume of blood loss or the condition of the woman, the spectrum of the condition can vary from inconvenient to fatal. However, in developed countries around $1 \%$ of postnatal women undergo surgical uterine evacuation for secondary postpartum haemorrhage and a further $1 \%$ are admitted to hospital but 
managed conservatively. ${ }^{3}$ Leaving aside any physical morbidity, it is generally acknowledged that the postnatal period is a time of significant psychological up-heaval for women and their families even without the added disruption of needing medical treatment and possibly admission to, or extra time in hospital. Secondary postpartum haemorrhage is, however, a topic that has received little attention because it is perceived as being associated with maternal morbidity rather than mortality. ${ }^{4} \quad$ Unlike primary postpartum haemorrhage, there is no clear definition for quantity of blood loss and this can vary from 'increased lochia' to massive haemorrhage. The diagnosis is therefore subjective, which may account for the variation in reported incidence. The reported overall incidence of secondary postpartum haemorrhage in the developed world varies from $0.47 \%$ to $1.44 \% .^{5}$

The etiology of secondary postpartum haemorrhage is diverse and management is dependent on identifying the cause and tailoring treatment appropriately. The diagnosis of secondary PPH is clinical. Usually there is abrupt onset of heavy bleeding 7-14 days after delivary. Around $10 \%$ of cases present with massive obstetrics haemorrhage. It is a diagnosis of exclusion. Ninety-five percent of women present within the first month after delivery, 19\% within 7 days, $41 \%$ in $8-14$ days, $23 \%$ in $15-21$ days and $12 \%$ in $22-28$ days. ${ }^{6}$ The amount of blood loss at presentation varies but most are hemodynamically stable. A thorough history will provide information relating to cause and should include details regarding parity, labor, mode of delivery, third-stage or puerperal complications and any relevant medical and family history. Clinical signs and symptoms at the time of presentation may include offensive lochia, abdominal cramping, uterine tenderness, pyrexia, enlarged uterus and an open cervical os. Secondary postpartum haemorrhage, which appears frequently to be linked with genital tract infection, still results in maternal death in developed countries albeit very occasionally.
As mentioned previously, the wicked situation occurs when $\mathrm{PPH}$ is presented in its secondary form, even if it affects only $1-2 \%{ }^{7}$ of postnatal women. The published work on the management of secondary PPH is limited compared with primary postpartum hemorrhage However, with falling maternal mortality rates, there is increasing interest and attention to maternal morbidity and the important topic of management of secondary postpartum haemorrhage. The majority of cases of secondary postpartum haemorrhage are associated with minor morbidities but may still require readmission to hospital, use of antibiotics and surgical intervention. In more extreme cases, major morbidity requiring hysterectomy, arterial ligation or radiological intervention is possible ${ }^{13}$ and maternal death may still result from massive secondary postpartum haemorrhage despite the use of all available interventions.

\section{Aims and objects}

1. To determine the various factor associated with secondary PPH

2. To evaluate the medical or surgical intervention needed in secondary PPH

\section{Method}

Study design: The study design was a prospective longitudinal study.

Study population: Women with bleeding per vagina with a diagnosis of secondary postpartum haemorrhage attending Regional Institute Of Medical Sciences, Imphal and subsequently getting admitted during the study period were included in the study.

Study Setting: The study was a hospital based study and was carried out in a tertiary hospital of Manipur, Regional Institute of Medical Sciences, Imphal.

Study Duration: Study was conducted during the period of November 2014 to April 2016.

Sample size: 65 admitted women diagnosed as a case of secondary $\mathrm{PPH}$ and who gave valid consent and who fulfill the inclusion and exclusion criteria was included in the study. 


\section{Inclusion criteria}

Women from 24 hours to 6 weeks following a pregnancy of at least 28 weeks gestation with a diagnosis of secondary $\mathrm{PPH}$.

\section{Exclusion criteria}

1) Women with bleeding per vagina less than 24 hour

2) Women with bleeding per vagina more than 6 weeks

3) Women less than 28 weeks of gestation

\section{Results}

In the study conducted at R.I.M.S Imphal from November 2014 to April 2016 there were 65 women who had secondary PPH, out of whom there were $25(38.5 \%)$ para-1, 20(30.8\%)para-2, $14(21.5 \%)$ para-3, 4(6.1\%) para-4 and $2(3.1 \%)$ more than para-5.The majority of women were in the age group of 20-30 year(63.1\%). The mean age was 27. \pm 6.04 . Parity in the present study did not influence the incidence of secondary PPH, and the distribution of its causes was the same in both primiparous and multiparous women. All patients were married and all were non smokers. In 17(26.2\%) secondary PPH presented less than 7 days of delivery, 24(36.9\%) within 8-14 days, $14(21.5 \%)$ within $15-21$ days,4(6.2\%) within 22 28 days and $6(9.2 \%)$ beyond 29 days with $\mathrm{P}=15.91 \pm 9.30$. Women with secondary $\mathrm{PPH}$ 52(80\%) was institutional and $13(20 \%)$ was home deliver, labour was induced in $5(7.7 \%)$ for maternal or foetal indication and was spontaneous in $60(92.3 \%)$. The duration of labour was less than 5 hours in 6(9.2\%), 6-10 hours in 50(76.9\%), 11 to 15 hours in $5(7.7 \%)$ and more than 15 hours 0.0 with Mean \pm SD:7.36 \pm 2.20 . In the study $46(70.8 \%)$ delivered by NVD, 7(10.8\%) by Emergency LSCS, 6(9.2\%)preterm Vaginal delivery, 3(4.6\%) vaginal birth after caesarean section, 2(3.1\%) ventouse vaginal delivery and $1(1.5 \%)$ by breech vaginal delivery. Active management of third stage of labour was done in all the cases by control cord traction but in 2(3.1\%).patient placenta was manually removed as it was adherent to the uterus. Women admitted with secondary $\mathrm{PPH}, 13(20 \%)$ delivered at home and 52(80\%) had institutional delivery out of which $17(26.2 \%)$ had third stage complication with more than two third having primary PPH $10(15.4 \%)$ and traumatic PPH 3(4.6\%). The cause of secondary postpartum haemorrhage was retained bits of membrane $24(36.9 \% \%)$, retained placental tissue $14(21.5 \% \%)$, purpural sepsis $8(12.3 \%)$ and subinvolution of the uterus $19(29.2 \%)$

Out of 65 women with secondary PPH,32 (49.2\%) women received medical treatment in the form of uterotonic drugs and administration of antibiotic. Antibiotic are commonly given to treat superimposed infection, thought to precipitate the haemorrhage. Uterotonic agents consist of oxytocin (synticinon), prostaglandin F2 alfa (carboprost) and methyl ergometrine. Misoprostol was also given as an alternative. Surgical treatment was given to $33(49.2 \%)$ women, check evacuation was done on 26(40\%) women, Dilatation and evacuation(D\&C) in $4(6.2 \%)$, placental tissue were removed digitally in $2(3.1 \%)$ where the cervical os was open and haemostaic suture was taken in $1(1.5 \%)$ women with bleeding from the right cervical angle.

In women presenting with secondary $\mathrm{PPH}$ $40(61.5 \%)$ was transfused blood,19(29.2\%) women received 1 unit of packed red blood cell (PRBC),14(21.5\%) received 2 unit of PRBC, $1(1.5 \%)$ received 3 unit $\mathrm{PRBC}$ and $5(7.7 \%)$ received 4 unit PRBC. only 1(1.5\%) women with chronic kidney disease (CKD) was transfused more than 9 units PRBC as she was on dialysis. In the study $24(36.9 \%)$ had risk factor like, anaemia $7(10.8 \%)$, gestational hypertension 6(9.2\%), multiple pregnancy $5(7.7 \%)$, premature rupture of membrane (PROM) 2(3.1), twice post caesarean section $2(3.1 \%)$, chronic kidney disease $1(1.5 \%)$ and HIV reactive $1(1.5 \%)$.

Secondary postpartum haemorrhage remains an important cause of maternal morbidity. Retained gestational products were more likely to be present when the placenta or membranes were noted to be incomplete at delivery or when there was a history of primary postpartum haemorrhage. As there seems to be no definite risk factor to 
identify retained products and the high rate of false positive diagnosis with sonography is high, management should probably be guided by the clinical presentation. Unnecessary operative procedure on the puerperal uterus should be avoided and caution should be taken in managing cases following caesarean section.

\section{Conclusion}

Unlike primary postpartum haemorrhage, there is no clear definition for quantity of blood loss for secondary postpartum haemorrhage and this can vary from 'increased lochia' to massive haemorrhage. This is not perhaps suprising, since the abnormality is one which usually causes distress and discomfort rather than danger and maternal morbidity rather than mortality.

A prospective study was conducted on 65 women presenting with bleeding per vaginum 24 hours to 6 week after delivery with the aim to determine the various factors associated with secondary postpartum haemorrhage and to evaluate the medical or surgical intervention needed. A detailed clinical history including parity, obstetrical history, duration of labour, mode and place of delivery and third stage complication was taken. General and systemic examination done and all the routine investigations including ultrasonography were carried out where necessary. Retained bits of membrane (36.9\%) and subinvolution of the uterus (29.2\%) was the two most common cause of secondary PPH followed by retained placental tissue $(21.5 \%)$ and puerperal sepsis $(12.3 \%)$. Medical treatment was given to $49.2 \%$ of women but $50.8 \%$ of the women with secondary PPH had surgical intervention

Finding from this study suggest that it would be useful to conduct a population-based prospective cohort study to verify the incidence of secondary PPH and to assess its predictive factors. Thus women having risks of secondary PPH would receive individual risk based counseling before their hospital discharge.

\section{References}

1. Dewhurst CJ. Secondary post-partum haemorrhage. $\mathrm{J}$ Obstet Gynecol $\mathrm{Br}$ Commonw 1966;73(1):53-8.

2. King PA, Duthie SJ, Ven D, Dong ZG, Ma HK. Secondary Postpartum Haemorrhage. Aust N Z J Obst Gynecol 1989;29(4):3948.

3. Glazener CMA, Abdalla M, Stroud P, Naji S, Templeton A, Russell IT. Postnatal maternal morbidity: extent, causes, prevention and treatment. $\mathrm{Br} \mathrm{J}$ Obstet Gynecol 1995;102:282-7.

4. Rome RM. Secondary post partum Haemorrhage. Br J Obstet Gynecol 1975;82: 289-92.

5. Hoveyda F,Mac Kenzie IZ. Secondary postpartum haemorrhage: incidence, morbidity and current management. $\mathrm{Br} \mathbf{J}$ Obstet Gyecol 2001;108:927-30.

6. Groom KM, Jacobson TZ. The management of secondary post partum haemorrhage. In: B-Lynch C, Keith LG, Lalonde AB, Karoshi $\mathrm{M}$, editors. A textbook of postpartum haemorrhage: a comprehensive guide to evaluation, management and surgical intervention. Duncow: Sapiens Publishing; 2006. p. 316-24.

7. Marchant S, Alexander J, Thomas $\mathrm{P}$, Garcia J, Brocklehurst, Keene J. Risk factors for hospital admission related to excessive and/or prolonged postpartum vaginal blood loss after the first $24 \mathrm{~h}$ following childbirth. Pediatr Perinat Epidemiol 2006;20(5):392 -402.

8. Mulic-Lutvica A, Axelsson O. Ultrasound finding of an echogenic mass in women with secondary postpartum hemorrhage is associated with retained placental tissue. Ultrasound Obstet Gynecol 2006;28 (3):312-9.

9. Khong TY, Khong TK. Delayed postpartum haemorrhage: a morphologic study of causes and their relation to other 
pregnancy disorders. Obstet Gynecol 1993 ;82(1) :17-22.

10. Markos AR. Prostaglandin E2 suppositories in the treatment of secondary postpartum haemorrhage. J R Soc Med 1989;82:504-5.

11. Legrand AD, Rivière $\mathrm{O}$, Dossou $\mathrm{M}$, Vendittelli F. Risk Factors for Severe Secondary Postpartum Hemorrhages: A Historical Cohort Study. Birth 2015;42(3): 235-41.

12. Larsen JV, Janowski K, Krolilowski A. Secondary post partum haemorrhage due to uterine wound dehiscence. Cent Afr J Med 1995;41(9):294-6.

13. Neill AC, Nixon RM, Thornton S: A comparison of clinical assessment with ultrasound in the management of secondary postpartum haemorrhage. Eur $\mathbf{J}$ Obstet Gynecol Reprod Biol 2002;104:113-5.

14. Sengupta Dhar, Misra R. Postpartum Uterine Wound Dehiscence Leading to Secondary PPH: Unusual Sequelae. Case Rep in Obstet Gynecol 2012;2012:1-3.

15. Park HS, Shin JH, Yoon HK, Kim JH, Gwon DI, Ko GY et al Transcatheter Arterial Embolization for Secondary Postpartum Hemorrhage: Outcome in 52 Patients at a Single Tertiary Referral Center. J Vasc Interv Radiol 2014;25(11):1751-7.

16. Doumouchtsis SK, Papageorghiou, Arulkumaran S. Systematic Review of Conservative Management of Postpartum Hemorrhage: What to Do When Medical Treatment Fails. Obstet Gynecol Surv 2007;62(8):540-7.

17. Knight M, Callaghan WM, Berg C, Alexander S, Bouvier-Colle MH, Ford JB et al. Trends in postpartum hemorrhage in high resource countries: a review and recommendations from the International
Postpartum Hemorrhage Collaborative Group. BMC Pregnancy Childbirth 2009;9(55):1-10.

18. Fong A, Leake J, Pan D, Ogunyemi D. Demographic, institutional and obstetrical risk factors for postpartum haemorrhage mortality. J Obstet Gynaecol 2010;30:4705.

19. Weydert JA, Benda JA. Subinvolution of the placental site as an anatomic cause of postpartum uterine bleeding:a review. Arch Pathol Lab Med 1994;130:1538-42.

20. Al-Mehaisen L, Al-Kuran O, Amarin ZO, Matalka I, Beitawi S, Muhtaseb A. Secondary postpartum hemorrhage following placental site vessel Subinvolution:a case report. Arch Gynecol Obstet 2008;278:585-7.

21. Tadesse W, Farah N, Hogan J, D'Arcy T, Kennelly M, Turner MJ. Peripartum Hysterectomy in the first decade of the 21st century. J Obstet Gynaecol 2011;31: 320-1.

22. Lédée N, Ville Y, Musset D, Mercier F, Frydman R, Fernandez H. Management in Intractable Obstetric Haemorrhage:An Audit Study on 61 Cases. Eur J Obstet Gynecol 2001;94:189-96.

23. Carroli G, Cuesta C, Abalos E, Gulmezoglu AM. Epidemiology of postpartum haemorrhage: a systematic review. Best Pract \& Res Clin Obstet Gynecol 2008;22: 999-1012. 